that the sample is representative of the whole stool. The assumption that stools are homogeneous is obviously unwarranted, as has been amply demonstrated by this study. Moreover, after the ingestion of charcoal or carmine it is not infrequently found that only part of a stool is coloured by the marker. Presumably the same uneven distribution can occur with haemoglobin breakdown products, particularly when bleeding started and ceased abruptly. The investigations were not designed to elucidate the number of samples which should be tested to minimize the sampling error. Nevertheless, with all the other inaccuracies of chemical tests and the unpleasantness of working with fresh stools the results of the present investigation show that there may be no need to examine more than, say, three different parts of the same stool. If these do not agree, further samples should be examined. However, samples giving equivocal results were not the same for each test, and there is need for further investigation of the extent to which inhibitors and perhaps accelerators interfere with the chemical tests for occult blood.

In the investigation of a patient with suspected disease of the alimentary tract no value can be attached to the results of any of the chemical tests for occult blood alone, since the most sensitive will sometimes give a negative result in the presence of considerable bleeding and the least sensitive will sometimes give a positive result in a healthy patient. Greatest reliance should therefore be placed on the combined results of clinical, radiological, and endoscopic examinations. If, however, these are equivocal, a positive result from the use of the less sensitive tests, such as hematest or 15 " hemastix, suggests the presence of a lesion, but $20 \%$ of stools not containing clinically significant amounts of blood can give false-positive reactions. A negative result by a sensitive tesi, such as occultest or $30^{\prime \prime}$ hemastix, suggests no such lesion, but $10 \%$ to $20 \%$ of stools containing significant amounts of blood can give false-negative reactions.

If the results of chemical tests for occult blood were regarded as clinical signs to be interpreted along with all the other clinical evidence which in disease can be variable, inconstant, and liable to biological variation, then two tests might be used, one of low sensitivity to detect significant amounts of blood in stools, and the other of high sensitivity to distinguish stools containing negligible amounts of blood. Rather than use two different tests, hemastix might be read at 15 seconds and 30 seconds. However, it must be appreciated that there is a one-in-five chance that the result may be misleading, and it is questionable whether in these circumstances the chemical tests for occult blood should be retained in modern medicine.

\section{Summary}

The relative sensitivivty of an orthotolidine test, two tablet tests, and a strip test for occult blood in faces has been investigated.

In a separate series of investigations the results obtained with these tests have been compared with the amount of blood loss as estimated by an isotope method.

No value can be attached to the results of any of the chemical tests alone.

When equivocal results are obtained from clinical, radiological, and endoscopic examinations two tests might be used A positive result using a relatively insensitive test would suggest bleeding; and a negative result with a more sensitive test would suggest absence of bleeding. However, false-positive results with the former and false-negative results with the latter are common.

We acknowledge with gratitude the help with the radioactivity measurements given us by Dr. K. G. Leach, of the department of physics, King's College Hospital, and also that given by the nursing staff in helping so ably with the collection of specimens. We are particularly grateful to the Miles Ames Research Laboratories for a grant to provide for assistance by $S$. de Silva and to meet other incidental expenses. Dr. Geoffrey Walker, of the Miles Ames Research Laboratories, gave us much help in supplying reagents and giving us valuable advice and criticism. Mr. M. P. Curwen, of the department of medical statistics, St. Bartholomew's Hospital, was particularly helpful in his suggestions for presenting the results.

\section{REFERENCES}

Adler, O., and Adler, R. (1904). Hoppe-Seylers Z. physiol. Chem., 41, 59.

Bannerman, R. M. (1957). Brit. med. F., 2, 1032

Boas, I. (1901). Dtsch. med. Wschr., 27, 315.

Cameron, A. D. (1960). Gut, 1, 177.

Ebaugh, F. G., Clemens, T., Rodnan, G., and Peterson, R. E. (1958). Amer. 7. Med., 25, 169.

Gregersen, J. P. (1919). Arch. Verdau-Kr., 25, 169

Hughes, A. (1952). Brit. med. ₹., 2, 970.

Illingworth, D. G. (1963). M.D. Thesis, Edinburgh University.

Needham, C. D., and Simpson, R. G. (1952). Quart. F. Med., 21, 123.

Owen, C. A., Cooper, M., Grindlay, J. H., and Bollmann, J. L. (1954). Surg. Forum, 5, 663.

Steingold, L., and Roberts, A. A. (1961). Gut, 2, 75.

Thornton, G. H. M., and Illingworth, D. G. (1955). Gastroenterology, 28, 593.

van Deen (1861). Arch. holländ. Beitr. Nat. Heilk., 3, 227.

\title{
Spinal-cord Compression in the Malignant Lymphomas
}

\author{
R. A. IRVINE,* M.B., M.R.C.P. ; W. B. ROBERTSON, $\dagger$ M.D., B.SC.
}

Brit. med. F., 1964, 1, 1354-1356

Compression of the spinal cord complicating malignant lymphomas is not unknown and several reports in the literature attest to this (Davison and Michaels, 1930 ; Browder and de Veer, 1939 ; Verda, 1944). In most cases, however, the cord symptoms become evident late in the disease and are not the primary complaint or disability which brings the patient to hospital. Rosenberg et al. (1961) reviewed some 1,269 cases, of which $35(2.7 \%)$ had cord lesions but only two presented with cord involvement as the initial complaint.

For the purpose of this paper the term "lymphoma" is used to include Hodgkin's disease, reticulum-cell sarcoma, lymphosarcoma, and lymphatic leukaemia. It does not include mye- loma or myelogenous or monocytic leukaemia. Three cases of cord compression from this cause, in which neurological symptoms were the major complaint, are presented. A fourth case, probably caused by ectopic bone-marrow, is also reviewed because of its interest and because of the difficulty that arose in differentiating histologically the atypical marrow from lymphoma. These cases are also reported because of the rapidity with which the cord symptoms in two of them regressed under treatment; in the third partial recovery has been maintained for almost five years.

* Lecturer in Medicine, University of the West Indies, Jamaica. + Senior Lecturer in Pathology, University of the West Indies, Jamaica. 


\section{Case 1-Hodgkin's Disease}

A 23-year-old Jamaican male of mixed negro and European stock was admitted to the University College Hospital of the West Indies on 16 January 1962 . Fourteen months prior to admission he had developed a persistent cough with progressive dyspnoea, hoarseness, and ankle oedema. Nine months later his legs became weak and within a further two months he was paralysed completely in both legs.

At the time of admission he was found to have all the features of superior mediastinal obstruction. The lymph nodes in the posterior triangles of the neck were enlarged and there was splenomegaly. Both legs were completely paralysed and spastic, and there was loss of sensation to all modalities up to a level at T 6 .

The mediastinal obstruction was shown on chest $x$-ray examination to be due to enlarged nodes. Biopsy of an axillary lymph node showed the typical picture of Hodgkin's disease. A lumbar puncture on 31 January showed the fluid was xanthochromic, with a pressure of $60 \mathrm{~mm}$. of cerebrospinal fluid. There were no cells, but the protein content was $500 \mathrm{mg} . / 100 \mathrm{ml}$. Serological tests for syphilis were negative in the blood and cerebrospinal fluid. $X$-ray films of the spine showed no abnormality. The $\mathrm{Hb}$ on admission was 10.6 g./100 ml. ; W.B.C. 5,500/c.mm. (neutrophils $89 \%$, lymphocytes $5 \%$, monocytes $6 \%$ ).

Because of the intense dyspnoea a myelogram was not performed and he was treated with mersalyl, digitalis, and chlorambucil, $10 \mathrm{mg}$. daily. The last-named drug was continued up to a total of $1,940 \mathrm{mg}$. Within seven days of starting therapy some movement returned to the toes of both feet; thereafter progress was rapid and in a further three weeks the patient could walk if supported. He was discharged from hospital and when seen in the follow-up clinic four months after the original admission he could walk slowly without any help. Unfortunately his mediastinal mass did not regress objectively although he was free of dyspnoea and cough. He died suddenly at home in August 1962. Necropsy was not performed.

\section{Case 2-Lymphosarcoma}

This patient, a 30-year-old negro, was admitted to hospital on 18 August 1959 . Since 1952 he had suffered from three attacks of low back pain, all of which cleared up spontaneously. In February 1959 he bent over to field a ball while playing cricket and was seized with intense back pain which gradually radiated around his waist and up to his shoulders. This was followed in two months by severe constipation. Two weeks before admission he became incontinent of urine with persistent haematuria.

At the time of admission to a surgical ward there was slight but detectable weakness in his peronei, glutei, and hamstrings, with anaesthesia around the anus and loss of both ankle-jerks. Cystoscopy revealed a severe cystitis which was presumed to be the cause of his haematuria. The $\mathrm{Hb}$ was 6.6 g.; M.C.H.C. $25 \%$; W.B.C. 12,900 (neutrophils $49 \%$, lymphocytes $45 \%$, monocytes $2 \%$, eosinophils $4 \%$ ). $X$-ray examination of the pelvis showed a dense sclerosis of the lumbar spine and sacrum. A lumbar puncture performed on 14 September revealed clear fluid under $80 \mathrm{~mm}$. cerebrospinal fluid pressure with 20 cells and $350 \mathrm{mg}$. of protein per $100 \mathrm{ml}$. Tests for syphilis in blood and cerebrospinal fluid were negative. Iliac crest biopsy and a biopsy of one of four tiny subcutaneous abdominal nodules revealed the histological appearance of lymphosarcoma. A myelogram performed on 15 September showed an obstruction to the flow of iophendylate from L 4 to $\mathrm{L} 2$. This was a diffuse lesion, the oil passing the obstruction in droplets.

The patient was transferred to a medical ward on 12 October by which time he was completely paralysed in both legs. The glutei, hamstrings, and quadriceps were wasted and both legs were spastic, with sustained ankle clonus. Knee and ankle reflexes were absent and there was anaesthesia around the anus. He had bedsores on the sacral region and over the dorsal spine and was incontinent of urine and faeces. There was a persistent burning pain in the anus and rectum requiring powerful analgesics for relief.

Treatment was begun on 19 October with chlorambucil, $10 \mathrm{mg}$. daily, and continued for 22 days. By the end of the course the subcutaneous nodules had disappeared, and on discharge on 5 December he could walk unaided. The power had returned to his legs and all reflexes were present. He had had no further treatment. Up to May 1963 he was back at full duty as a public health inspector. His $\mathrm{Hb}$ averaged about $13.9 \mathrm{~g}$. and the only disability was partial impotence. A small area of anaesthesia around the anus remained. The $x$-ray picture of the lumbo-sacral spine was unchanged.

\section{Case 3-Lymphosarcoma}

A male negro school-teacher aged 56 was admitted to hospital on 10 November 1958. He had noticed lumps in his groin 15 months previously, for which he had consulted many doctors. Five days before admission his right leg "felt dead," and this rapidly progressed to a complete paraplegia of both legs. He was not incontinent of urine.

On admission there was generalized lymphadenopathy with tender indurated areas on the abdominal wall. He had a spastic paraplegia with a sharp sensory level at $\mathrm{T} 12$. His $\mathrm{Hb}$ was $13.4 \mathrm{~g}$; W.B.C. 3,950 , with a normal differential count. A lumbar puncture revealed clear cerebrospinal fluid under $90 \mathrm{~mm}$. pressure. There was a slow rise to $140 \mathrm{~mm}$. on jugular compression, with a slow fall on release of the pressure. The fluid contained 2 cells and $300 \mathrm{mg}$. of protein per $100 \mathrm{ml}$. Tests for syphilis were negative. $X$-ray films of the spine were normal. A biopsy of a lymph node showed lymphosarcoma.

Treatment was begun with tretamine, and he received a total of $32.5 \mathrm{mg}$. between 25 November and 14 December. There was no improvement in his paraplegia, and on 8 January 1959 he was put on prednisone, $15 \mathrm{mg}$. t.i.d., and mercaptopurine, $50 \mathrm{mg}$. t.i.d. The dose of prednisone was reduced to $5 \mathrm{mg}$. q.i.d. and maintained at that level until 18 April, when he refused to take both drugs and would not co-operate with the physiotherapists. He was discharged from hospital on 23 January little improved, but he did consent to continue with his steroid therapy.

Over the years he regularly attended follow-up clinics and still took prednisone, $5 \mathrm{mg}$. t.i.d. Improvement out of hospital had been gradual and by 23 February 1963 he was able to walk a few steps unaided and he could get about quite actively on crutches or with a walking-stick. Signs of spasticity remained and his lymph nodes had nearly all disappeared except for a large clump of glands in both groins. He was convinced that his symptoms were improved on prednisone, although there was no doubt that it had produced a mild psychotic reaction.

\section{Case 4-Extramedullary Haemopoiesis}

A negro Jamaican woman aged 34 first came to our attention in August 1954. At that time she was admitted to hospital because of a seven-day history of backache rapidly progressing to numbness of the feet and inability to walk. On examination she was found to have a spastic paraplegia with a sensory level at $\mathrm{T} 10$. Both the liver and spleen were enlarged and there was a hypochromic microcytic anaemia with $\mathrm{Hb}$ of $8.4 \mathrm{~g}$. The cerebrospinal fluid contained $1 \mathrm{cell} / \mathrm{c} . \mathrm{mm}$. and $100 \mathrm{mg}$. of protein per $100 \mathrm{ml}$. Cerebrospinal fluid and blood tests for syphilis were negative. $X$-ray films of the spine showed generalized osteoporosis but no collapsed vertebrae. The bone-marrow was hyperplastic and normoblastic. Without any specific therapy her recovery was rapid, and within six weeks she was walking normally.

A similar episode occurred in March 1959, when she again became paraplegic over a period of four weeks. By the time of admission to hospital on 18 March her symptoms had begun to improve, but she had a spastic paraparesis with an ill-defined sensory level at $\mathrm{T} 7$. Her $\mathrm{Hb}$ was $8.7 \mathrm{~g}$. and the cerebrospinal fluid showed no abnormality. Hepatosplenomegaly was unchanged. On this occasion studies on the blood of herself and of members of her family confirmed a diagnosis of thalassaemia major. Within two weeks all symptoms had subsided, but the signs of pyramidal damage remained.

In January 1961 she was admitted to the obstetric wards at the 31 st week of pregnancy with a history of two weeks' backache and inability to walk. Again there was a spastic paraplegia with a sensory level at $\mathrm{T} 10$. The cerebrospinal fluid was xanthochromic with a cell-count of $1 / \mathrm{c} . \mathrm{mm}$. and a protein of $600 \mathrm{mg} . / 100 \mathrm{ml}$. Because of an undifferentiated sacral mass (which on biopsy proved to have a fibrous capsule with haemorrhage and inflammatory cells but no specific features) a lower-segment caesarean section was performed in due course. After this a myelogram confirmed a complete block to the flow of iophendylate at T 9 . 
On 9 March a laminectomy was performed. The bone of the laminae had a thin cortex with a medullary cavity stuffed with marrow. The extradural space was filled with purple tissue resembling bone-marrow, and this appeared to be the cause of the cord compression. Biopsy of the mass showed it to be composed of (extramedullary) haemopoietic tissue. However, as it also contained numerous large atypical cells of the reticulum-cell type, some lymphocytes, plasma cells, and rather numerous eosinophils, a diagnosis of Hodgkin's disease was offered (Figs. 1 and 2). No typical Reed-Sternberg cells were seen. From the subsequent history and review of the slides we are now convinced that the mass is non-neoplastic.

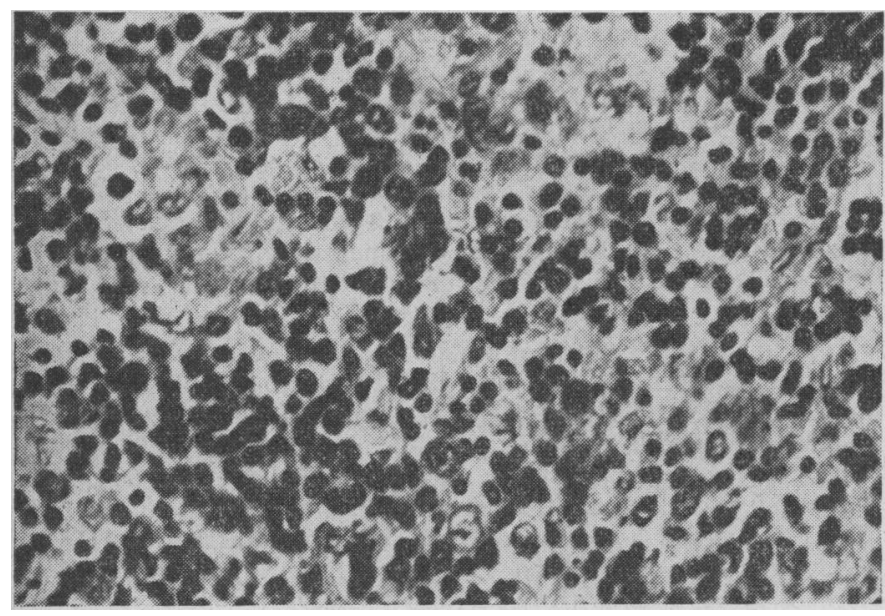

FIG. 1.-Case 4. Hypercellular extramedullary haemopoiesis, normoblasts predominating.

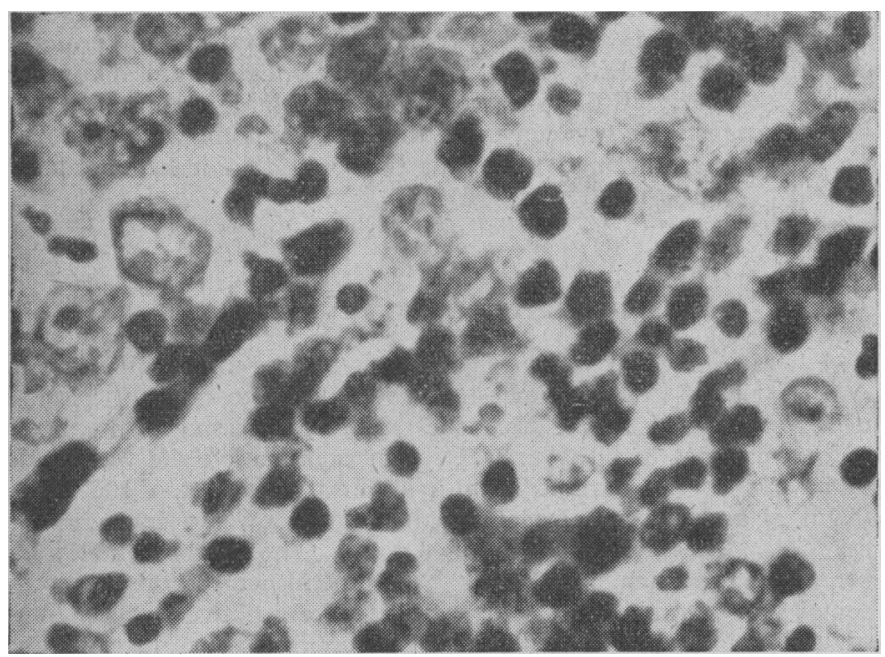

FIG. 2.-Case 4. Hypercellular extramedullary haemopoiesis. Note large number of reticulum type cells. (H. and E. $\times 1,000$.)

Treatment was begun with chlorambucil, $10 \mathrm{mg}$. daily, but this had to be curtailed because of a falling white-cell count. She was subsequently given a course of deep $x$-ray therapy to the spine. At first there was no improvement, and on discharge from hospital in August 1961 paraplegia in flexion and an apparently hopeless prognosis were present. However, while at home her symptoms gradually improved. She at first refused to return to hospital for follow-up, but was persuaded to do so on 21 March 1963, about 18 months later. When examined she was perfectly strong and was walking normally, doing a full day's work. Her paraplegia had resolved over a period of eight months. Only some spasticity and extensor plantar responses persisted.

\section{Discussion}

Malignant tumours of the reticulo-endothelial system appear to be common in Jamaica. During the period 1958-62 the Jamaica Cancer Registry, University of the West Indies, listed some 224 cases from the Kingston and St. Andrew area, which has a population of approximately 400,000. Registration of lymphomas are exceeded only by those of cancer of stomach, breast, and uterus. The natural history and the pathology of the lymphomas in Jamaica differ in no way from the accepted pattern.

Lymphomas may involve the spinal cord in a variety of ways (Russell and Rubinstein, 1959). There may be direct extension into the epidural space by retrograde spread along the lymphatics of the cord which drain to the retroperitoneal nodes. This was perhaps the route of spread in the first patient, who had massive mediastinal node involvement. There may be direct invasion of near-by vertebrae with eventual invasion of the epidural space-for example, in the second patient, who apparently had diffuse infiltration of his pelvis and lumbar spine. The growth may also arise from lymphoid elements of the epidural space or may extend into the epidural space by direct extension through the intervertebral foramina.

Whatever the mode of spread it is interesting that in our cases there was prompt amelioration of the cord symptoms on chemotherapy. At the same time there was little objective evidence of similar regression in tumour tissue involving the other structures. In Case 1 there was still massive enlargement of the mediastinal lymph nodes, while in Case 2 there was $x$-ray evidence of bone disease almost four years after the initial treatment. In the third patient the lymph nodes of the groin, although fibrotic, were still very much enlarged. When one considers that the blood supply to the spinal cord is not particularly rich, especially in the mid-thoracic region, it is difficult to explain these remarkable successes with chemotherapy. It is tempting to ascribe the paraplegic symptoms of these patients to vascular insufficiency produced by the pressure of the growing tumour. Direct invasion of the cord substance would seem unlikely as the damage produced would in all probability be irreversible. The clinical presentations, with slow onset and gradual progression, and the amelioration with treatment indicate some form of interference with the function of the cord which had not progressed to actual destruction of nerve tissue. In the absence of necropsy material this point cannot be determined.

Most of the published reports on similar cases recommend laminectomy and radiotherapy as the treatment of choice (Love et al., 1954). It would appear from our experience with these cases in Jamaica that chemotherapy, which is now simple and easier to administer, is worthy of more extensive trial.

\section{Summary}

Three cases of paraplegia complicating malignant lymphomas are reported. All were treated with chemotherapy. The results have been very encouraging, and a plea is made for more intensive trials of chemotherapy when there is cord involvement with lymphoma.

A fourth case of paraplegia due to extramedullary haemopoiesis is included in this report. Cord compression from this cause is rare. However, interpretation of biopsy specimens may be misleading unless this condition is borne in mind. This is precisely what happened in the present case, where the biopsy appearances were thought to be compatible with a malignant lymphoma. Recovery was complete but treatment was probably unnecessary.

\section{REFERENCES}

Browder, J., and de Veer, J. A. (1939). Arch. Neurol. Psychiat. (Chic.), 41, 328 .

Davison, C., and Michaels, J. J. (1930). Arch. intern. Med., 45, 908. Love, J. G., Miller, R. H., and Kernohan, J. W. (1954). Arch. Surg., 69, 66

Rosenberg, S. A., Diamond, H. D., Jaslowitz, B., and Craver, L. F. (1961). Medicine (Baltimore), 40, 31

Russell, D. S., and Rubinstein, L. J. (1959). Pathology of Tumours of the Nervous System, pp. 64-70. Arnold, London.

Verda, D. J. (1944). Surg. Clin. N. Amer., 24, 1228 